drische Schwefel ist also unter allen Formen des Schwefels die beständigste.

Die Zustände des Schwefels, der aus irgend einer Verbindung abgeschieden wurde, sind an die Natur dieser Verbindung selbst geknüpft, sie richten sich nach der Natur des Körpers, mit welchem der Schwefel verbunden war, oder mit welchem er sich zu verbinden im Begriff steht. Wenn der Schwefel die Rolle eines electro-negativen zündenden Elementes, analog dem Chlor und Sauerstoff, spielt, so stellt er sich unter der Form des krystallisirten, octaëdrischen, im Schwefelkohlenstoff löslichen Schwefels dar. Spielt er im Gegentheil die Rolle des electro-positiven verbrennlichen Elementes, analog dem Wasserstoft und den Metallen, so sehen wix denselben unter der Form des amorphen unlöslichen Schwefels auftreten. Z. B. eine wässerige Lösung von Schwefelwasserstoff liefert bei der Electrolyse eine Abscheidung des Schwefels am positiven Pole, derselbe ist krystallisirbar und völlig löslich in CS2. Eine wäss̀erige Lösung von schwefliger Säure, ebenso die concentrirte Schwefelsüure $\mathrm{HO}, \mathrm{SO}^{3}$, liefern bei der Electrolyse eine Abscheidung von Schwefel am negativen Pole; dieser Schwefel ist amorph und unlöslich im Schwefelkohlenstoff. (M. Berthelot, Ann. de Chim. et de Phys. 3.Sér. Avril 1857. T. XLIX. pag. $430-475$.)

Dr. H. Ludwig.

\title{
Bildung des unlöslichen Schwefels durch Wärme.
}

Die Erscheinungen, welche der Schwefel unter dem. Einflusse der Wärme darbietet, sind sicher eine Folge seines Ueberganges aus einem dem krystallisirbaren Schwefel entsprechenden Zustande in einen anderen, dem amorphen oder unlöslichen Schwefel entsprechenden Zustand. Dieser Uebergang findet bei $170^{\circ} \mathrm{C}$. statt. Der Schwefel, langsam unter dieser Temperatur abgekühlt, nimmt den dem krystallisirbaren Schwefel entsprechenden Zustand wieder an, er wird wieder zu electro-negativem Schwefel. Aber wenn die Abkühlung sehr rasch geschieht, so scheint der fest und cohärent gewordene Schwefel einen Molecularzustand zu behaupten, der dem auf $170^{\circ} \mathrm{C}$. erhitzten Schwefel entspricht, d.h. dem electro-positiven, verbrennlichen Schwefel. Man kann diesen electro-positiven Zustand dauernd machen, wenn man den Schwefel während seines Erhärtens mit electro-negativen Körpern in Contact lässt, z. B. mit schwefliger Säure oder mit 
Einwirkung der conc. Schwefelsäure auf Blutlaugensalz. 311

Salpetersäure. (M. Berthelot, Ann. de Chim. et de Phys. 3. Sér. Avril 1857. T. XLIX. p. 476-486.)

Dr. H. Ludwig.

\section{Gewinnung des Schwefels aus Gyps.}

Dr. L. Elsner hat Schwefelcalcium durch Glühen von Gyps mit Kohle erhalten, mit verdünnter Salzsäure behandelt und das Gas in schwefligsaures Wasser geleitet; er erhielt nach dem vorsichtigen Schmelzen 34 Proc. Schwefel, während der Theorie nach in dem Schwefelcalcium 44 Proc. Schwefel enthalten sind. Aus 1 Centner Schwefelcalcium würde man demnach 36 Pfund Schwefel erhalten können. (Elsner's chem.-techn. Mitth. 1854-1856. S. 187. - Polyt. Centrbl. 1857. S. 602.) E.

\section{Rinwirkung der concentrirten Schwefelsäure auf Blut- langensalz.}

Chr. Grimm und G. Ramdohr fanden, dass man beim Erhitzen von 7 Theilen fein gepulvertem Blutlaugensalz mit $9 \mathrm{Th}$. concentrirter Schwefelsäure nicht, wie Fow n es angiebt, reines, sondern Kohlensäure und schweflige Süure enthaltendes Kohlenoxydgas erhält. Sie beobachteten indessen das Auftreten der Kohlensäure stets nur zu Anfang der Operation gleichzeitig mit schwefliger Säure und bemerkten, dass wenn die erhitzte Mischung von Blutlaugensalz und Schwefelsäure zu schäumen anfängt, die Entwickelung des reinen Kohlenoxydgases verhältnissmässig lange Zeit von selbst vor sich geht. Es ist deshalb gut, vorsichtig zu erwärmen und das Feuer, sobald dieser Punct eintritt, unter dem Kolben zu entfernen. Bei späterer Erhitzung erhält man Kohlenoxyd, welches durch schweflige Säure verunreinigt ist. Beim weiteren Verlauf der Operation bildet der Rückstand im Kolben eine klare Flüssigkeit, aus der sich weisse perlmutterartig glänzende Krystallblättchen ausscheiden. Dieselben lassen sich aus dem Rückstande leicht durch Ver. dünnung mit Wasser gewinnen und auf einem Filtrum sammeln.

Die Analyse des aus der oben angeführten Mischung von Blutlaugensalz und Schwefelsäure erhaltenen Gases ergab, dass 100 Volumen desselben aus $11,79 \mathrm{CO}^{2}$ und $\mathrm{SO}^{2}$ und 88,21 CO bestehen. 